\title{
Police Station Network Implementation
}

\author{
Prof. M. E. Ingale ${ }^{1}$, Mayur B. Thakare ${ }^{2}$, Kamini D. Sagar ${ }^{3}$, Supriya M. Ghuge ${ }^{4}$ \\ Assistant Prof., Electronics \& Telecommunication, Sandip Institute of Technology \& Research Centre, Nashik, India ${ }^{1}$ \\ UG Student of Dept. E \& TC, Sandip Institute of Technology \& Research Centre, Nashik, India ${ }^{2,3,4}$
}

\begin{abstract}
In this network implementation we are supposed to access multiple PC's without using internet with LAN and the protocols that we are using are TFTP and FTP for sharing data and this whole network system is designed for security purpose and for handling system with command.
\end{abstract}

Keywords: FTP, TFTP, LAN, Routers, Switch.

\section{INTRODUCTION}

In different area of the police station network we are planning to use protocols of multiple routing The project initiates from the different police station department to the control room. This technology also implements to let the admin part and the important terms and staff would be allowed to utilize the network resources at the time of urgency. The important security concepts implemented so that the forbidden information of the police record would not be accessible for unknown person.

\section{-HISTORY}

In past years this network implementation system is designed for the hospitals airports and hotels. This system have not implemented for the police department so we decided to implement this for security and fast work process.

In past days and in recent days also the SATARK and CCTNS are used to share information but these networks are not easy to handle and not very secure.

Because the internet is required for run the whole system also security problem is being faced by the users so we come to plan the network implementation for police dept. without using internet and with high security.

\section{-EARLIER WORK}

We had gone to the commissioner office to know about what system they are using to share data regarding to crime and criminal records. We came to know that they are using CCTNS network, in that software hacking chances are more and internet problems are present and access by any common person so therefore the data is not secure. So we plan to implement such network system that will be more secure and easily handle but can't be access by common user.

\section{-PROPOSED SYSTEM}

Purpose is to connect PCs using communication protocols. So we have make the network first using packet tracer software and have to set the IP addresses in short we are making our own system without using internet with several commands use for the networking system are handle by user. This system is proper way to stop hacking process and the other problem faced by different application which are recently used by department of police for recording purpose.

Fig. Network implemented in CISCO Packet Tracer. Software Used: Packet Tracer 5.3.2

Operating System: Any OS

\section{Packet tracer :}

It is utilized in training purpose and research for simple computer network simulations. Cisco Systems created a tool and provided for free distribution to faculty, students, participated in the Cisco Networking Academy.

\section{Features :}

Array of simulated Application Layer protocols and basic routing with RIP and EIGRP to the current CCNA curriculum are supported by current version. Its aim is to provide a realistic simulation of networks, the application utilizes small number of features found Thus, and i t is unsuitable for modelling production networks. With version 5.3, new features were added, including BGP, which is $\mathrm{n}$ part of the CCNP curriculum.

\section{PACKET TRACER (version 5.3.2):}

User gets global view of network through simulation by logical workspace where devices are added, linked, configured and important for wireless labs, where the distance parameter determines whether device is able to connect or not to other device.

\section{-PROTOCOL}

FTP:

FTP uses TCP. TCP layers handle Data and control information transmission.

It is complex than TFTP, thus require larger memory footprint.

User data and control information separated by TCP connections. 
Fig. FTP Packet Transfer

\section{TFTP:}

Authentication is not provided. No connections as UDP used. A simple lock-step protocol packet needs to acknowledge.

Uses the equally simple UDP transport protocol, TFTP clients has very small footprint and thus suited for use in boot loaders.

Fig. TFTP Session between a client and server.

\section{COMPARISION OF FTP AND TFTP}

\begin{tabular}{|l|l|l|l|}
\hline $\begin{array}{l}\text { SR } \\
\text { NO }\end{array}$ & $\begin{array}{l}\text { PARAM } \\
\text { ETERS }\end{array}$ & FTP & TFTP \\
\hline 1. & $\begin{array}{l}\text { Abbrevia } \\
\text { tion }\end{array}$ & $\begin{array}{l}\text { File transfer } \\
\text { protocol }\end{array}$ & $\begin{array}{l}\text { Trivial file } \\
\text { transfer } \\
\text { protocol }\end{array}$ \\
\hline 2. & $\begin{array}{l}\text { Authentic } \\
\text { ation }\end{array}$ & $\begin{array}{l}\text { Required in the } \\
\text { ftp for } \\
\text { communication } \\
\text { between client } \\
\text { and server }\end{array}$ & $\begin{array}{l}\text { No } \\
\text { authentication } \\
\text { is required in } \\
\text { TFTP }\end{array}$ \\
\hline 3. & Service & $\begin{array}{l}\text { Uses TCP } \\
\text { service which is } \\
\text { a connection } \\
\text { oriented service }\end{array}$ & $\begin{array}{l}\text { UDP service } \\
\text { which is } \\
\text { connectionless } \\
\text { service }\end{array}$ \\
\hline 4 & Software & $\begin{array}{l}\text { Software is } \\
\text { larger than } \\
\text { TFTP }\end{array}$ & $\begin{array}{l}\text { Software is } \\
\text { smaller than } \\
\text { FTP and fits } \\
\text { into read only } \\
\text { memory of } \\
\text { diskless } \\
\text { connection }\end{array}$ \\
\hline 5. & $\begin{array}{l}\text { Complexi } \\
\text { ty }\end{array}$ & More complex & Less complex \\
\hline
\end{tabular}

\section{-SYSTEM OVERVIEW}

\section{A. Advantages}

1. Small space required for implementation.

2. Power consumption is less.

3. This will provide safety and reliability to user

\section{B. future scope}

1. 1. We can implement this project for multiple police stations over one city.

2. We also use this same system for other purpose

\section{CONCLUSION}

This project is based on the networking protocols which are used to access multiple PCs for system reliability. By using this system the work of police department will become faster and secured regarding data of crime and criminal.

\section{ACKNOWLEDGEMENT}

The work procedure in this report would not have been completed without the encouragement and support of many people who gave their precious time and encouragement throughout this period. We would like to sincerely thank to our project guide Prof. M. E. Ingale for his guidance and for the patience he showed us during the process of preparation of project from initial conception to the final design and implementation.

We would also like to extend our gratefulness to the Head Of Department E and TC Dr. Mrs. G. M. Phade Lab and Library In Charge for kindly granting us to access lab. We would also like to thank to the teaching staff and non teaching staff who helped us from time to time with their own experience and also we would like to express our gratitude to the core of our heart, principal Dr. S. T. Gandhe Sir for being supportive and always encouraging.

\section{REFERENCES}

[1] E. Lear, "Uniform Resource Identifier(URI) Scheme and Applicability Statement for the (TFTP)", RFC, 3617, 2003.

[2] Nur Nabila Mohamed, Habibah Hashim, Yusnani Mohd Yussuff, Mohd Anuar Mat Isa, Securing TFTP packet: A preliminary study, in 2013 IEEE $4^{\text {th }}$ Control and System Graduate Research Colliquium, pp. 158-161, 2013.

[3] Data communication and networking by frozen. 